\title{
MODELLING THE ASSESSMENT OF TRAFFIC RISK AT LEVEL CROSSINGS OF LITHUANIAN RAILWAYS
}

\author{
Gintautas Bureika ${ }^{1}$, Eduardas Gaidamauskas², Jonas Kupinas ${ }^{3}$, \\ Marijonas Bogdevičiuss ${ }^{4}$, Stasys Steišūnas ${ }^{5}$ \\ ${ }^{1,5}$ Dept of Railway Transport, Vilnius Gediminas Technical University, Vilnius, Lithuania \\ ${ }^{2} J S C$ 'Intento', Vilnius, Lithuania \\ ${ }^{3} J S C$ 'S4ID', Vilnius, Lithuania \\ ${ }^{4}$ Dept of Transport Technological Equipment, Vilnius Gediminas Technical University, Vilnius, Lithuania
}

Submitted 10 November 2015; resubmitted 9 May 2016; accepted 17 June 2016; first published online 24 October 2016

\begin{abstract}
The article discusses the problem of railway safety management and the criteria for evaluating the traffic risk described in various scientific publications. The research aims to assess the risk posed to railway infrastructure objects and to create a model for safety risk evaluation. The research on the traffic safety risk with respect to the infrastructure of the rail transport system was divided into three stages. The Plan-Do-Check-Act (PDCA) model can be used for investigating the problem of managing railway traffic safety risks in the Lithuanian railways. The main threats to railway infrastructure objects are defined, and the catalogue of technical parameters of level crossings of the Lithuanian railways is presented. The maximum allowable train speed, the intensity of railway and road traffic, as well as the size (width) and visibility of level crossings from the train driver's cab are chosen as the main criteria for evaluating the vulnerability of a level crossing. The logistic regression method has been applied to rank and assess the safety of level crossings of the Lithuanian railways. The validity of the model developed in the present work for assessing traffic safety risks at level crossings of Lithuanian railways is about $86 \%$. The suggested risk evaluation model is flexible and can be easily adapted for the evaluation and monitoring of safety risk of other elements pertaining to railway infrastructure. Finally, the basic conclusions and recommendations are provided.
\end{abstract}

Keywords: railway safety; traffic accident; traffic threats; vulnerability; logistic regression.

\section{Introduction}

Ensuring safety of passenger and freight transportation by railway is an important factor in the increase of its attractiveness and competitiveness. Safety and security are the most important and basic requirements for passenger and freight transport. These factors are even more significant than travel time and pricing, while for the railway transport, they make a complex and complicated problem. Since the safety of railway traffic involves problems in several areas, associated with moving rolling-stock, automation, as well as the alarm signalling system and infrastructure, the railway transport system is vulnerable and faced with many potential risks (Bonvicini et al. 1998). The analysis and assessment of risks are necessary to ensure the safety of railway transport. It is also the basis for decision-makers, allowing them to take measures for the maintenance of the system safety.
The vulnerability analysis is mainly associated with the identification of the vulnerable elements of the network, while the risk analysis mainly refers to finding out the accidents, which are most probable and their potential consequences. The risk analysis is a more comprehensive work, which needs more fundamental data (El Koursi et al. 2007). Tu et al. (2015) presented a comprehensive study on the reliability analysis method for safety-critical avionics system by using the dynamic fault tree approach based on the Markov chain.

To achieve the effective control of railway traffic and to ensure its safety in a country, all the objects (elements) of the railway infrastructure should be classified and ranked according to their hazardousness. The main factors determining rail traffic safety should be identified, and the priority measures, and prompt actions should be taken to decrease the potential risks to railway traffic safety (De Giorgio et al. 2006).

Corresponding author: Gintautas Bureika

E-mail: gintautas.bureika@vgtu.lt 
Level crossings are objects of railway infrastructure that are usually associated with serious problems as many collisions with the road transport vehicles and other objects take place and cause casualties or serious injuries of people. Some authors are focused on case studies to obtain realistic assessments of current practices in highway-rail grade crossing assessments (Davey et al. 2008).

The control of the rail transport safety is aimed at saving human lives and health, as well as their property. It should also help to reduce the harmful effect of rail transport on the environment and ensure the interaction between rail transport systems of various countries. Using the available multiple criteria evaluation methods, researchers analyse not only the quality of rail transportation of people and goods but also solve risk management problems associated with traffic safety of rail transport. The researchers of Lithuania offered to apply the Analytic Hierarchy Process (AHP) approach to the evaluation of risks particular to various objects of the railway infrastructure (Bureika et al. 2013).

Other researchers focused on case studies to obtain realistic assessments of current practices in highway-rail grade crossing inspections (Liu et al. 2011; Oh et al. 2006). Podofillini et al. (2006) thoroughly investigated various aspects of rail traffic risks referring to the control of the rail maintenance quality in a railway line. Evans (2003), Forsberg and Björnstig (2011) described the statistical estimation of railway accidents and compared it with the estimate produced by the railway industry using a risk model, while the Chang and Ju (2008) compared passenger and freight transportation. In the period of 2001-2007, the Australian Railway Traffic Risk Management Model ALCAM was created and implemented as an assessment tool designed to prioritise the improvement of the level crossing safety.

Safety performance of the existing roads should be increased by targeting investments to the highest accident concentration sections and (or) to the road sections or crossings with the highest accident reduction potential. Recently, various models for evaluating railway traffic risk and for its management have been offered. The scientific articles (Ishak et al. 2010; Lerner et al. 2002) presented the level crossing research methods, safety modelling, and analysis. The $\Pi$-tool based on the Petri net approach was used to build the model. This model was tested at ten critical level crossing locations in South Australia. Other approaches, including a nonparametric statistical method and the Hierarchical TreeBased Regression (HTBR), which are used for exploring train-vehicle crash prediction and the analysis of risks at passive highway-rail grade crossings, are discussed in the articles of Yan et al. (2010) and Saccomanno et al. (2004). The authors used the database of the Federal Railroad Administration, while their research focused on 27 years of the train-vehicle accident history in the US since 1980 until 2006.

Hu et al. (2010) analysed several studies about the application of logit or probit models and their versions to fit the data regarding accident severity on roadway segments. Compared to accident risk analysis in terms of accident frequency and severity particular to a highway system, the investigation of the factors contributing to traffic accidents at a Railway Level Crossing (RLC) seems to be more complicated because of additional highway-railway interactions. A generalized log-it model with stepwise variable selection was used instead to identify the explanatory variables, which were strongly associated with the severity of collisions. Hence, the fitted model was used to predict the level of accident severity, given a set of values in the explanatory variables.

Austin et al. (2002) used the negative binomial regression to develop an alternate model for the prediction of highway-rail crossing accidents. This model is much more promising compared to the model previously used by the US Department of Transportation, which was based on the accident prediction formula, and had the limitations related to the complexity of the three-stage formula and the decline in the accuracy of the accident prediction model over time. Researches in the modelling of crash risk have advanced from univariate to bivariate approaches, which simultaneously model crash frequency and severity by using multivariate data models, such as multivariable Poisson (Ye et al. 2009, 2013) and generalized Poisson models (Famoye et al. 2004), because the two dependent variables are closely related to each other.

Miranda-Moreno et al. (2005) investigated the relative performance of three alternative models, including the traditional negative binomial model, the heterogeneous negative binomial model, and the Poisson lognormal model. In particular, this work focused on the impact of the choice of two alternative prior distributions (i.e., gamma versus lognormal) and the effect of allowing variability in the dispersion parameter on the outcome of the analysis.

Most of the rail traffic accidents are associated with the human factor, involving the violation of traffic regulations on a road or a railway by a vehicle or failure to observe traffic regulation signals and traffic signals by a locomotive driver, as well as possible drowsiness, tiredness, the use of alcohol, etc. (Lobb 2006; Cacciabue 2005). However, specialists of railway traffic safety believe that the construction of some protective structures, such as railings, ramps, platforms, etc., and the provision of other facilities, including pedestrian crossings, lighting equipment, traffic signs, signalling systems, animal crossings, etc., could help to increase traffic safety of railways.

The article by Wullems (2011) discusses major obstacles for the adoption of Low-Cost Level-Crossing Warning Devices (LCLCWDs) in Australia and reviews those trialled in Australia and internationally. The argument for the use of LCLCWDs is that, for a given investment, more passive level-crossings can be used while ensuring greater safety benefits across the rail network. Since the improvement of safety at RLC is costly and funds are always limited, it is important to search for 
cost-effective alternative solutions. There are low-cost innovative RLC-protection systems available worldwide, with the opportunities for application in Australia due to their effectiveness and appropriateness (Tey at al. 2011).

There is much literature on modelling the risks at level crossings. Models have existed for more than 70 years (Austin et al. 2002). Various statistical models are used to examine the relationships between crossing accidents and the features of crossings. Oh et al. (2006) compares the accident models developed in the US and the safety effects of crossing elements obtained using the Korean data. The technique for the estimation of statistical risk, which was based on the explanatory variables in the regression, was described by Mok and Savage (2005). Two regressions were performed by the authors. The first regression was based on the number of accidents in a state in a given year at public crossings, involving a motor vehicle, while the second regression presented the number of deaths caused by these incidents. The people killed were mainly highway users, but there were also fatal injuries suffered by train crew members and passengers.

The present article describes the model for assessing and controlling risks to the safety of Lithuanian RLC based on the logistic regression, which was created by the authors. During the investigation, the efforts were made to create a dynamic model of risk management and control for RLCs, which meant that the model had to be easily adjusted to suit the latest statistical data on traffic accidents in the country. The notion 'traffic accident' in the presented model includes collision between rolling stock and road vehicles or horse carriages, death or injuries of pedestrians, bicycle riders, and trespassers.

\section{Research Object and the Considered Problems}

The research on the traffic safety risk with respect to the infrastructure of the rail transport system was divided into three stages as follow:

- The initial stage involved storing (recording) the data on the objects (elements) of the railway infrastructure, their classification, and identification of traffic accident threats, as well as expert evaluation of the potential damage, collection of data on the risks of the investigated objects and determination of the importance of various risk factors.

- The analysis of rail traffic risks. This stage was dedicated to the analysis of the risks to a particular object or a set of objects (their sample) based on the associated and recorded risk factors (criteria).

- Traffic risk management. This stage involved the selection of means, methods, and devices, which can be recommended for the reduction of risks to a particular object or a group of objects based on particular criteria.

During the investigation, the data were collected on the Lithuanian RLCs as the objects exposed to traffic safety risks. A schematic diagram of railway traffic risk analysis is presented in Fig. 1.

The Plan-Do-Check-Act (PDCA) model can be used for the investigation of the problem related to the management of railway traffic safety risks in the Lithuanian railways. This cycle is represented by an iterative four-step management method, which is widely used in business for controlling and improving the processes

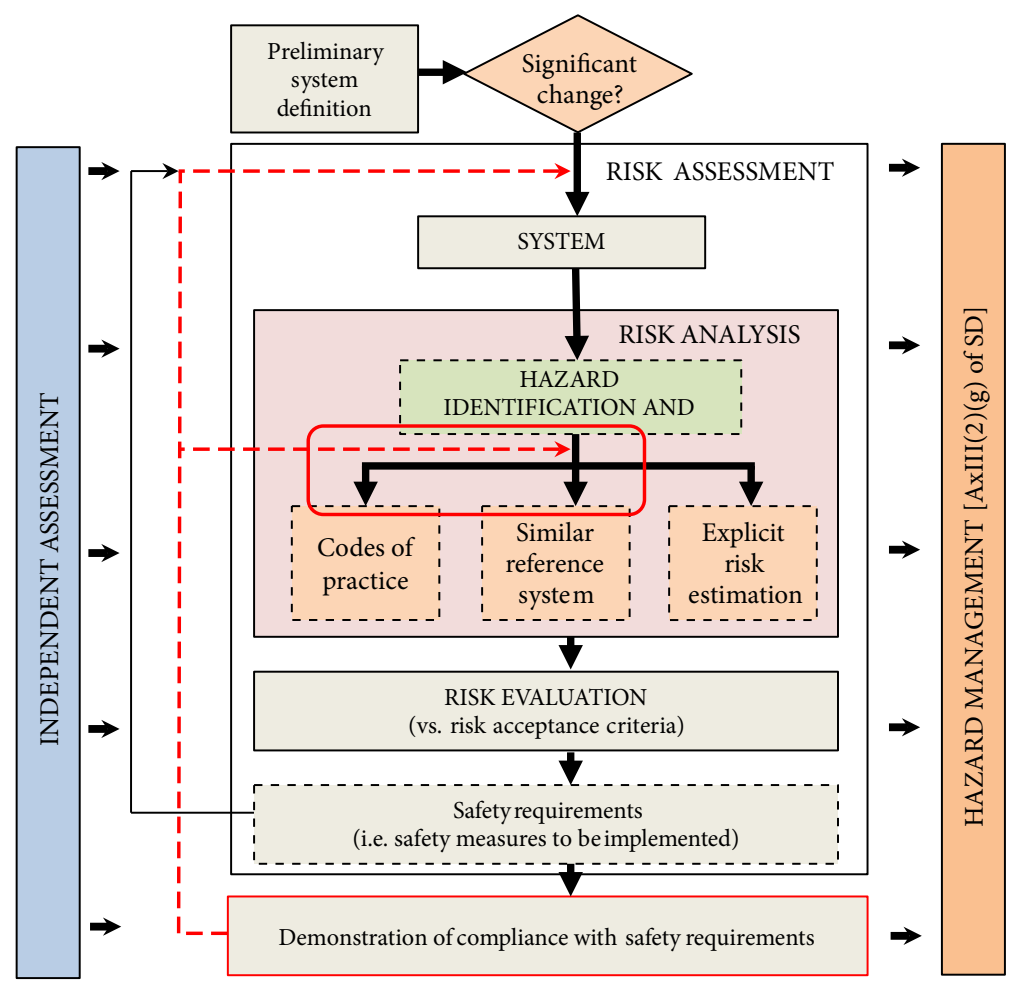

Fig. 1. Schematic diagram of the railway safety risk analysis (El Koursi et al. 2007) 
and products. The cycle for the adaptation of the PDCA model for the investigation of the management of railway traffic safety risks and hazards is shown in Fig. 2.

At this stage of research, the Authors focused only on a part of the PDCA cycle. The presented study includes two parts of PDCA: the first, which is the RLC Risk Assessment (System Definition, Hazard Identification, Risk Assessment), and the second, which is the RLC Risk Control (Audit \& Monitoring, Corrective Measurements, Accident Reporting \& Learning).

Prior to the assessment of traffic safety risks to the objects that belong to the infrastructure of the railway system, it is necessary to define the aims of risk analysis and to identify the criteria for the selection of the objects of this analysis. The values of some particular parameters of the objects can be chosen as their evaluation criteria. A possibility to select the objects for the analysis allows us to use more flexible approaches to the examination of risks posed to a particular type of objects, or the objects of a particular locality.

Another important factor is the choice of the period to be analysed. It is clear that risks can change with time. Therefore, the analysis performed over a short period allows us to identify risk objects at that particular time, while the choice of a longer period allows for identifying the trends of risk development.

The next step of the analysis is the choice of threats to be considered (Bureika et al. 2013). The analysis can involve all threats that are significant at the moment or only some of them. To ensure the comprehensiveness of the obtained results and the possibility to analyse them, the methods of their classification (or grouping) should be determined.

The classifier, which was earlier used for choosing the objects of the infrastructure for analysis, can be used for grouping its results. This type of classification allowed us to compare various objects with each other with respect to risks posed to them (e.g. to compare the safety risks to various structures, buildings, crossings, trains, etc.).

The real time risks to railway transport safety can be statistically estimated for some particular or all considered objects (their groups), taking into account each selected threat. If it is found that a traffic accident, the cause of which has not been eliminated yet, is directly related to the considered threat, the real-time risk $R_{\text {real }}$ is calculated from the equation:

$$
R_{\text {real }}=I \cdot T_{\text {max }},
$$

where: $I$ is the damage, which can be caused by the considered threat in the case of its realization; $T_{\max }$ is the highest probability of threat realization for the selected object.

In other cases, the real-time risk to an object is equal to the object's statistical risk $R_{\text {real }}=R_{\text {stat }}$. If a group of objects is considered, this total risk is determined, taking into account the object of the group exposed to the highest risk.

The algorithm for the assessment of the safety risk to the Lithuanian RLCs is described below.

\section{Investigating the Risk Level of Railway Crossing}

To determine the safety risk level of railway transport as well as its variation and impact on the traffic safety, the Authors have chosen the most critical objects of the railway infrastructure in the country. RLCs appeared to be the most critical objects in Lithuania from the perspective of railway traffic safety.

At present, the state enterprise $\mathrm{AB}$ 'Lietuvos geležinkeliai' (JSC Lithuanian Railways) has 523 RLCs in its possession, 93 of which are found on the sidings. It has been determined that 384 RLCs are automatically regulated, while 139 RLCs are not. It has also been found

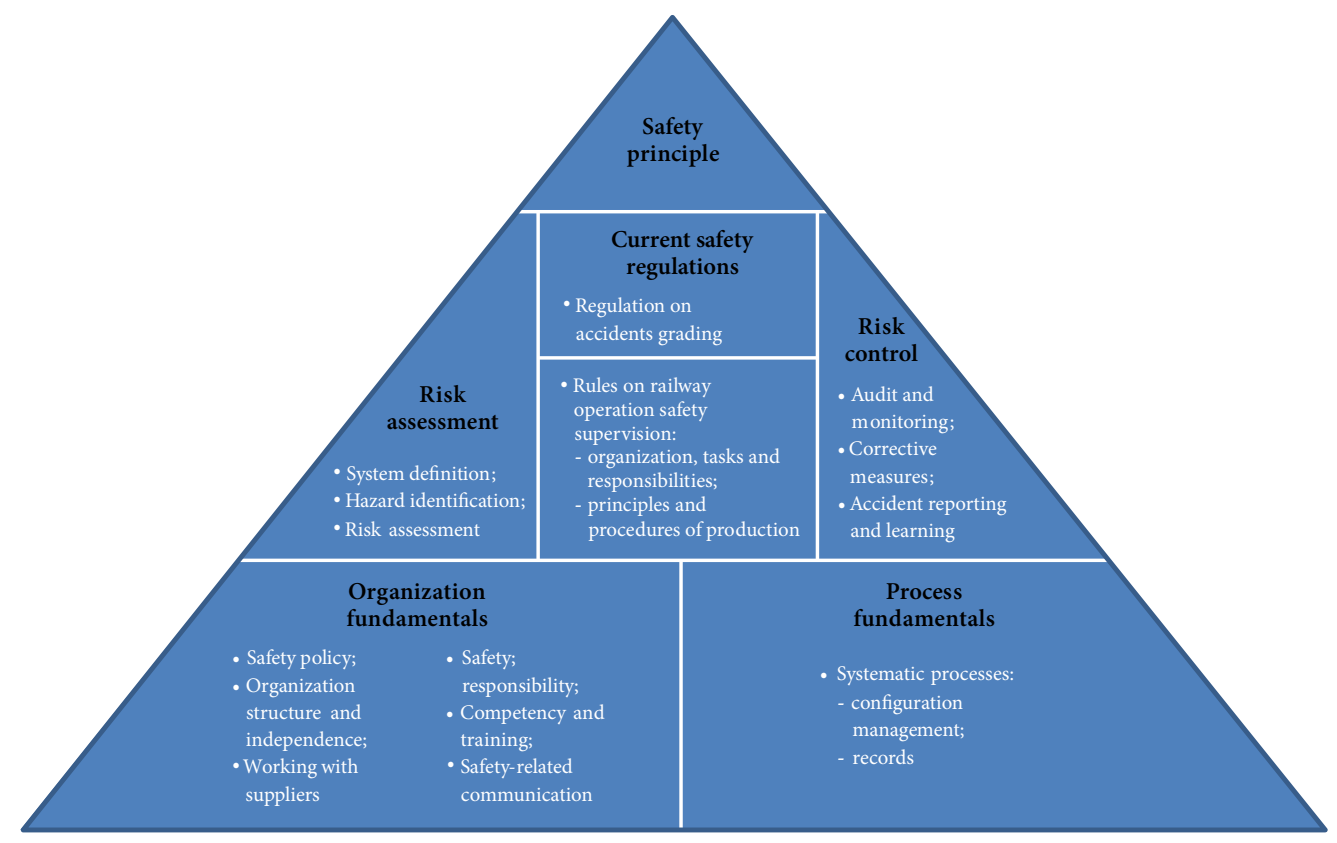

Fig. 2. Principle PDCA cycle in the evaluation of railway safety (El Koursi et al. 2007) 
that 48 RLCs are guarded, while 475 of them are not. Compared to the European countries, the density of RLC distribution in Lithuania is medium with one RLC per $4.17 \mathrm{~km}$ of the railway track compared to the highest density of RLCs of one RLC per $1.08 \mathrm{~km}$ in Norway, and the lowest density of one RLC per $7.38 \mathrm{~km}$ found in Latvia. In addition, it has been found that $75 \%$ of RLCs controlled by the JSC Lithuanian Railways have signalling systems. According to this comparison, all RLCs in Norway are equipped with signalling systems, while Ireland has only $20 \%$ of RLCs equipped with these systems.

General factors (criteria) determining the safety of RLCs are as follow:

1) single or double railway track;

2) the railway under repair: the railway track is closed or not closed during the repairs;

3) the largest allowable number of the trains to pass per day;

4) the highest allowable speed of the trains: for passenger and freight trains;

5) the operational (actual average) speed of trains;

6) the real number of trains passing per day;

7) the intensity of road traffic per RLC;

8) the availability of the automatic block signalling systems;

9) the type of the RLC: guarded or non-guarded;

10) the location of the RLC: in a settlement or elsewhere;

11) the availability of barriers on the RLC;

12) visibility of the RLC from both directions;

13) the availability of lighting on the RLC;

14) meteorological conditions: rain, fog, snow, etc.;

15) the state of the locomotive's control and signalling systems.

Note. The above mentioned RLC traffic risk factors are presented in a random order, i.e. are not ranked on any impact weightiness.

The determinative factors of the accident rate at RLCs and their safety risks can be evaluated based on the following five parameters: the intensity of rail and road traffic, the visibility of an RLC from the locomotive driver's cab, the highest allowable speed of the train, the traffic intensity per RLC, and the number of tracks at RLC (the width).

The statistical data on the technical characteristics of 523 Lithuania RLCs, which are closely related to the hazardousness of the RLCs, have been collected and used as the criteria in the model for assessing traffic risks at the RLCs. The following information was included in the catalogue of data on the Lithuanian RLCs: the identification number of the RLC, the branch of the Lithuanian railway system's infrastructure, the location of the RLC ( $\mathrm{km}$ and distance from the station), the railway stretch, the road or street crossed, the size (width) of the RLC, the highest daily traffic intensity on the RLC, the category of the RLC and its visibility from the locomotive driver's cab. All these data on Lithuanian RLCs were entered into the MS Excel catalogue (Table 1).
A survey of the specialists in railway operation and traffic safety helped Authors to identify the main five factors (criteria) determining the risk to RLCs. They are as follows:

1) the width of the RLC;

2) the highest allowable speed of the train;

3) the load on the RLC (the intensity of rail and road traffic);

4) visibility of the RLC from the locomotive driver's cab from both directions;

5) the RLC category.

The intensity of rail and road traffic on the RLC depends on its category.

According to rail and road traffic intensity, public RLCs of Lithuania are divided into four categories (Table 2).

Then, the Authors of the article, based on the above-described criteria, assessed the safety risk of the RLCs, using the method of logistic regression.

\section{Determining the Risks to Railway Traffic Safety by Using a Logistic Regression}

\subsection{Logistic Regression Method}

Logistic regression is used for modelling binary outcome variables such as credit default or warranty claims. It is assumed that the binary response, $Y$, takes on the values of 0 and 1 , with 0 representing failure and 1 representing success.

The logistic regression function models the probability that the binary response is a function of a set of the predictor variables:

$$
\log \frac{p_{i}(X)}{1-p_{i}(X)}=b_{0}+b_{1} \cdot x_{i 1}+b_{2} \cdot x_{i 2}+\ldots+b_{k} \cdot x_{i k} \text {. }
$$

Solving for $p$, this gives:

$$
p_{i}(X)=\frac{e^{z\left(\vec{x}_{i}\right)}}{1+e^{z\left(\vec{x}_{i}\right)}},
$$

where:

$$
z\left(\vec{x}_{i}\right)=b_{0}+b_{1} \cdot x_{i 1}+b_{2} \cdot x_{i 2}+\ldots+b_{k} \cdot x_{i k}
$$

$X=\left[x_{i 1}, x_{i 2}, \ldots, x_{i k}\right]$ are independent variables.

In practice, the regression coefficients; $B=$ $\left[b_{0}, b_{1}, b_{2}, \ldots, b_{k}\right]$, are unknown and are estimated by maximizing the likelihood function:

$$
L(B)=\prod_{i=1}^{n} p_{i}(X)^{y_{i}} \cdot\left(1-p_{i}(X)\right)^{1-y_{i}}
$$

Then, the log-likelihood turns the product into sums:

$$
\begin{aligned}
& l(B)=\sum_{i=1}^{n} y_{i} \cdot \ln \left(p_{i}(X)\right)+\sum_{i=1}^{n}\left(1-y_{i}\right) \cdot \ln \left(1-p_{i}(X)\right)= \\
& \sum_{i=1}^{n} y_{i} \cdot\left(\ln \left(p_{i}(X)\right)-\ln \left(1-p_{i}(X)\right)\right)+\sum_{i=1}^{n} \ln \left(1-p_{i}(X)\right)= \\
& \sum_{i=1}^{n} y_{i} \cdot z\left(\vec{x}_{i}\right)-\sum_{i=1}^{n} \ln \left(1+e^{z\left(\vec{x}_{i}\right)}\right) .
\end{aligned}
$$




\begin{tabular}{|c|c|c|c|c|c|c|c|}
\hline 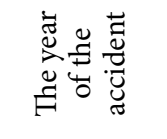 & ठे & 完 & 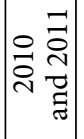 & 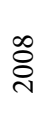 & & 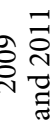 & 究 \\
\hline 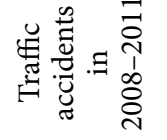 & + & + & + & + & + & + & + \\
\hline
\end{tabular}

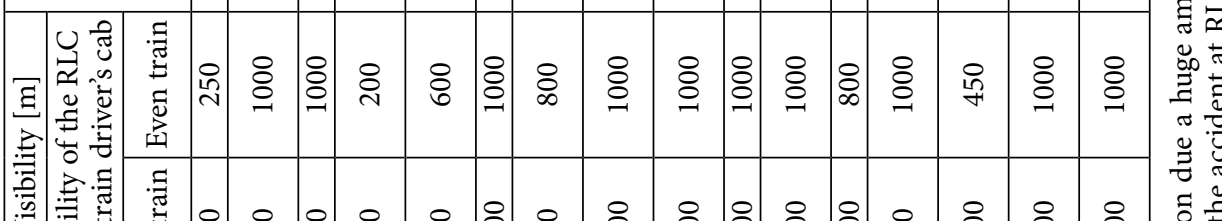

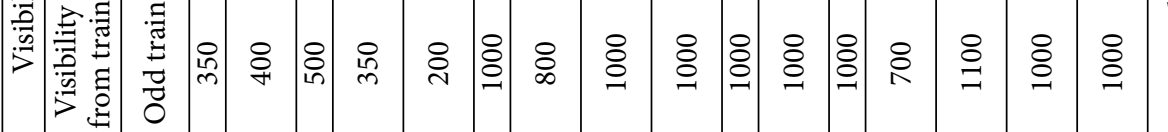

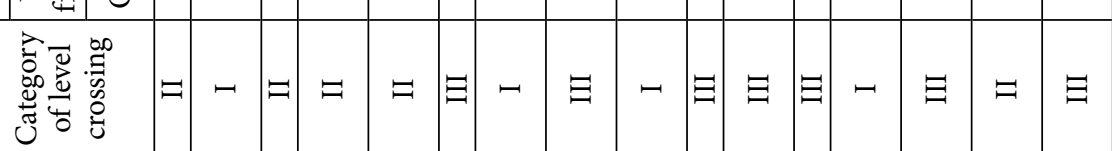

เัต

苛



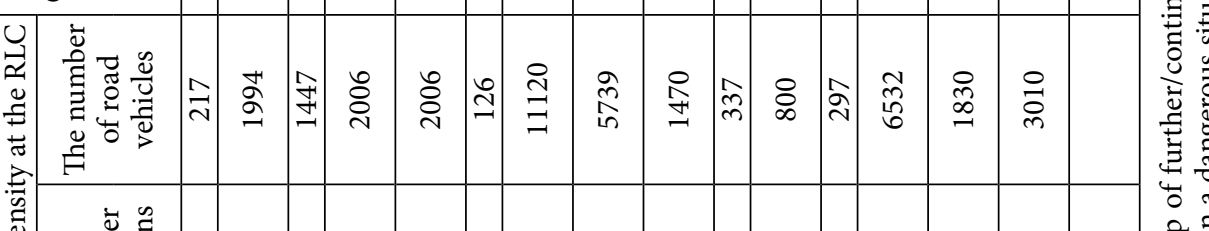
政

Е 寻苛

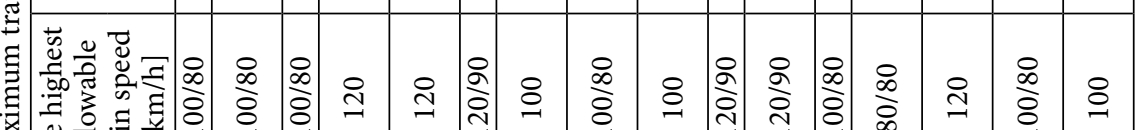

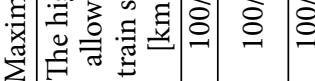

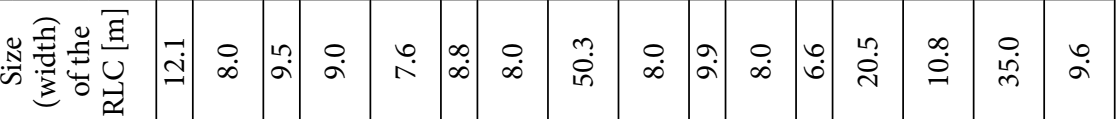

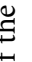

范

\begin{tabular}{|c|c|c|c|c|c|c|c|c|c|c|c|c|c|c|c|c|}
\hline 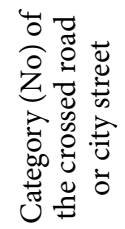 & 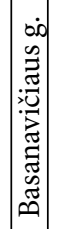 & \begin{tabular}{c}
$\widehat{乏}$ \\
\multirow{f}{*}{}
\end{tabular} & $\mid$\begin{tabular}{l}
$\infty$ \\
\multirow{4}{\downarrow}{} \\
$\mid$
\end{tabular} & $\vec{\circ}$ & $>$ & + & 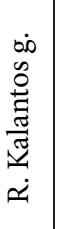 & $\begin{array}{l}\text { से } \\
\text { i }\end{array}$ & 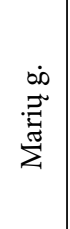 & 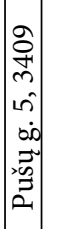 & & 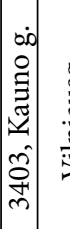 & 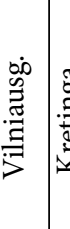 & 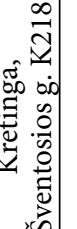 & 点 & 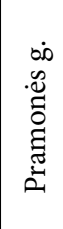 \\
\hline
\end{tabular}

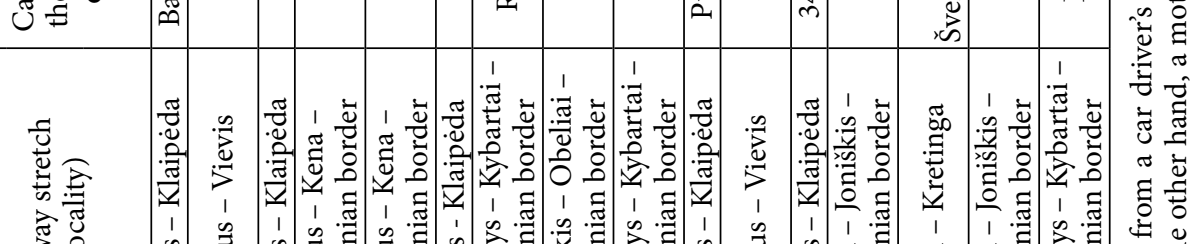

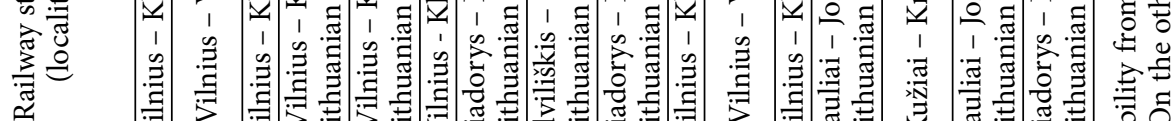
象

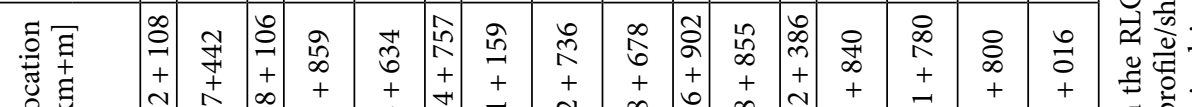

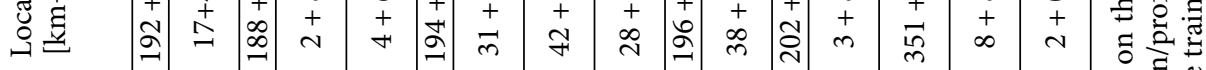

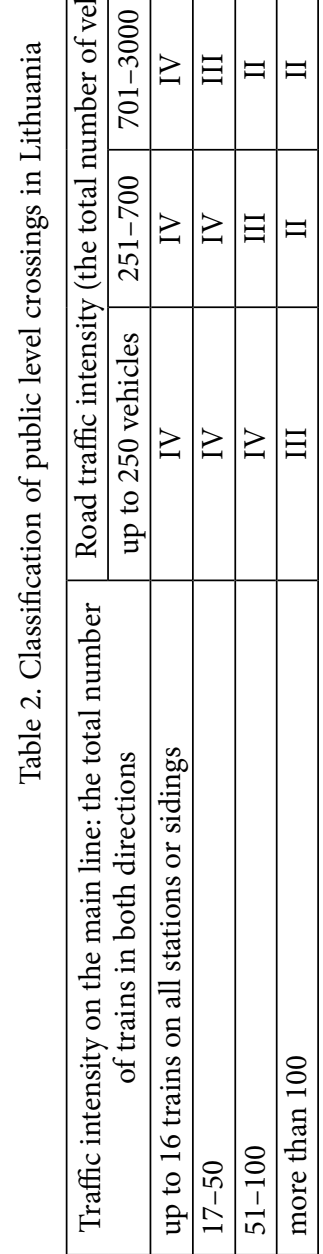

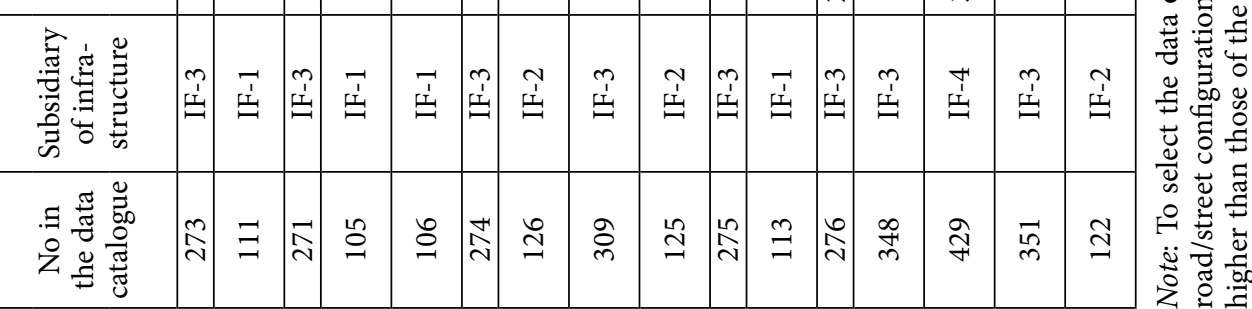

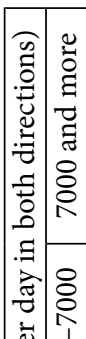

\&

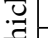

एे 
Usually, to find the maximum likelihood estimates, we have to differentiate the $\log$-likelihood with respect to the parameters, to set the derivatives equal to zero, and to solve the equation. To start the solution, take the derivative with respect to a component of $B$, say $b_{i}$ :

$$
\left\{\begin{array}{l}
\frac{\partial l(B)}{\partial b_{0}}=\sum_{i=1}^{n}\left(y_{i}-p_{i}(X)\right) \\
\cdots ; \\
\frac{\partial l(B)}{\partial b_{j}}=a, \quad j=1,2, \ldots, k
\end{array}\right.
$$

where:

$$
\begin{aligned}
& a=\sum_{i=1}^{n} y_{i} \cdot x_{i j}-\sum_{i=1}^{n} \frac{e^{z\left(\vec{x}_{i}\right)}}{1+e^{z\left(\vec{x}_{i}\right)}} \cdot x_{i j}= \\
& \sum_{i=1}^{n}\left(y_{i}-p_{i}(X)\right) \cdot x_{i j} .
\end{aligned}
$$

This is a transcendental equation, and there is no closed-form solution. We can, however, approximately solve it numerically. These equations, known as the likelihood equations, are expressed as follow:

$$
\left\{\begin{array}{l}
\sum_{i=1}^{n}\left(y_{i}-p_{i}(X)\right)=0 \\
\ldots ; \\
\sum_{i=1}^{n}\left(y_{i}-p_{i}(X)\right) \cdot x_{i j}=0, \quad j=1,2, \ldots, k .
\end{array}\right.
$$

The value of $B$ given by the solution to these equations is called the maximum likelihood estimate and will be denoted by $\hat{B}$. In general, the symbol ' $\wedge$ ' denotes the maximum likelihood estimate of the respective quantity.

\subsection{Approaches to Model Fitting}

The result of fitting the model of RLC traffic risk calculation is expressed as follows:

$$
\begin{aligned}
& \log \frac{p_{i}(X)}{1-p_{i}(X)}=-3.6707+0.0412 \cdot x_{i 1}+ \\
& 0.0109 \cdot x_{i 2}+0.0144 \cdot x_{i 3}-0.006 \cdot x_{i 4}+ \\
& 1.4971 \cdot x_{i 5}+0.79 \cdot x_{i 6}+0.9242 \cdot x_{i 7}
\end{aligned}
$$

and by solving it with the variable $p_{i}$, we get:

$$
p_{i}(X)=\frac{e^{z\left(\vec{x}_{i}\right)}}{1+e^{z\left(\vec{x}_{i}\right)}}=\frac{e^{a}}{1+e^{a}},
$$

where:

$$
\begin{aligned}
& a=-3.6707+0.0412 \cdot x_{i 1}+0.0109 \cdot x_{i 2}+0.0144 \cdot x_{i 3}- \\
& 0.0006 \cdot x_{i 4}+1.4971 \cdot x_{i 5}+0.79 \cdot x_{i 6}+0.9242 \cdot x_{i 7} \\
& b_{0}=-3.6707 \\
& b_{1}=0.0412 \\
& b_{2}=0.0109 \\
& b_{3}=0.0144 \\
& b_{4}=0.006
\end{aligned}
$$

$b_{5}=1.4971$

$b_{6}=0.79$;

$b_{7}=0.9242$

are the values:

$\sim\left(\begin{array}{c}\sim \overrightarrow{ } \\ i\end{array}\right)={ }_{0}+{ }_{1} \cdot{ }_{i 1}+{ }_{2} \cdot{ }_{i 2}+\ldots+{ }_{k} \cdot{ }_{i k}$

of the calculated coefficients; $x_{i 1}$ is the width of the RLC $[\mathrm{m}] ; x_{i 2}$ is the highest set speed of the locomotive $[\mathrm{km} / \mathrm{h}] ; x_{i 3}$ is the number of the trains passing by per day; $x_{i 4}$ is visibility of RLC from locomotive driver's cab, distance $[\mathrm{m}] ; x_{i 5}$ is equal to 1 for RLC of category 1 (otherwise, it is equal to 0 ); $x_{i 6}$ is equal to 1 for RLC of category 2 (otherwise, it is equal to 0 ); $x_{i 7}$ is equal to 1 for RLC of category 3 (otherwise, it is equal to 0 ).

The bounds of the variation of variables used in the logistic regression model are given in Table 3.

Table 3. Range of variation of the parameter values of the considered RLCs

\begin{tabular}{|l|c|c|}
\hline \multicolumn{1}{|c|}{ RLC parameter } & $\begin{array}{c}\text { Minimal } \\
\text { value }\end{array}$ & $\begin{array}{c}\text { Maximal } \\
\text { value }\end{array}$ \\
\hline Width of the RLC [m] & 1.6 & 50.3 \\
\hline The highest train speed [km/h] & 5 & 120 \\
\hline $\begin{array}{l}\text { The number of trains passing } \\
\text { by per day }\end{array}$ & 1 & 202 \\
\hline $\begin{array}{l}\text { The number of road vehicles } \\
\text { passing by per day }\end{array}$ & 0 & 2600 \\
\hline $\begin{array}{l}\text { Visibility of RLC from the train } \\
\text { driver's cab [m]: } \\
\text { - even railway line } \\
\text { - odd railway line }\end{array}$ & 0 & 3000 \\
\hline
\end{tabular}

The allowable (standard) visibility of RLC is at least $1000 \mathrm{~m}$. The highest allowable speed of passenger trains in Lithuania is $120 \mathrm{~km} / \mathrm{h}$, while for freight trains it is $100 \mathrm{~km} / \mathrm{h}$. Based on the logistic regression method, the safety risk probability was calculated for every RLC by using Eq. 8. The Lithuanian RLCs were ranked according to their hazardousness to identify the most dangerous of them. The results of calculating the safety risk level of the most dangerous RLCs in Lithuania (top 3\%) are presented in Table 4.

As shown by the data presented in Table 4, as many as eight RLCs of the 1st or 2nd category are found among the first ten RLCs. In the period 2008-2011, two traffic accidents (ranked 2nd and 7th) took place at each of the two level crossings of the 1st category. The RLCs of the 3 rd category were also included in the Top 15 because of traffic accidents that occurred in 2008-2011 (except for RLC No 274 in Radviliškis, the hazardousness of which increased with the train speed limit raised to $120 \mathrm{~km} / \mathrm{h}$ ). It is worth noting that, according to the logistic regression model, the most hazardous RLC in Lithuania belongs to the second category (RLC No 273 at the station of Radviliškis). The calculations have shown that this RLC is potentially most hazardous because the level of risk there reaches 0.813 . 
Table 4. Ranks assigned to Lithuanian RLCs according to traffic risks for 2012

\begin{tabular}{|c|c|c|c|c|c|c|c|c|c|c|}
\hline \multirow{3}{*}{ Rank } & \multirow{3}{*}{$\begin{array}{l}\text { No of } \\
\text { RLC in } \\
\text { the data } \\
\text { catalogue }\end{array}$} & \multirow{3}{*}{$\begin{array}{l}\text { Width } \\
\text { of the } \\
\text { RLC } \\
{[\mathrm{m}]}\end{array}$} & \multicolumn{3}{|c|}{$\begin{array}{l}\text { The highest daily traffic intensity } \\
\text { on the RLC }\end{array}$} & \multirow{3}{*}{$\begin{array}{l}\text { The RLC } \\
\text { category }\end{array}$} & \multirow{2}{*}{\multicolumn{2}{|c|}{$\begin{array}{l}\text { RLC visibility from the } \\
\text { locomotive driver's cab } \\
\text { (distance }[\mathrm{m}] \text { ) }\end{array}$}} & \multirow{3}{*}{$\begin{array}{c}\text { Traffic } \\
\text { accidents } \\
\text { in } \\
2008-2011\end{array}$} & \multirow{3}{*}{$\begin{array}{l}\text { Risk } \\
\text { level }\end{array}$} \\
\hline & & & \multirow{2}{*}{\begin{tabular}{|c|} 
The highest \\
allowable train \\
speed $[\mathrm{km} / \mathrm{h}]$
\end{tabular}} & \multirow{2}{*}{$\begin{array}{c}\text { The number } \\
\text { of trains }\end{array}$} & \multirow{2}{*}{$\begin{array}{l}\text { The number } \\
\text { of vehicles }\end{array}$} & & & & & \\
\hline & & & & & & & Odd train & Even train & & \\
\hline 1 & 273 & 12.1 & $100 / 80$ & 202 & 217 & II & 350 & 250 & + & 0.813 \\
\hline 2 & 111 & 8.0 & $100 / 80$ & 139 & 1994 & $\mathrm{I}$ & 400 & 1000 & + & 0.733 \\
\hline 3 & 271 & 9.5 & $100 / 80$ & 169 & 1447 & II & 500 & 1000 & & 0.676 \\
\hline 4 & 105 & 9.0 & 120 & 124 & 2006 & II & 350 & 200 & & 0.614 \\
\hline 5 & 106 & 7.6 & 120 & 124 & 2006 & II & 200 & 600 & & 0.600 \\
\hline 6 & 274 & 8.8 & $120 / 90$ & 123 & 126 & III & 1000 & 1000 & & 0.524 \\
\hline 7 & 126 & 8.0 & 100 & 90 & 11120 & I & 800 & 800 & + & 0.515 \\
\hline 8 & 309 & 50.3 & $100 / 80$ & 10 & 5739 & III & 1000 & 1000 & + & 0.490 \\
\hline 9 & 125 & 8.0 & 100 & 90 & 1470 & I & 1000 & 1000 & & 0.486 \\
\hline 10 & 275 & 9.9 & $120 / 90$ & 108 & 337 & III & 1000 & 1000 & + & 0.481 \\
\hline 11 & 113 & 8.0 & $120 / 90$ & 100 & 800 & III & 1000 & 1000 & + & 0.433 \\
\hline 12 & 276 & 6.6 & $100 / 80$ & 106 & 297 & III & 1000 & 800 & & 0.416 \\
\hline 13 & 348 & 20.5 & $80 / 80$ & 18 & 6532 & I & 700 & 1000 & & 0.350 \\
\hline 14 & 429 & 10.8 & 120 & 40 & 1830 & III & 1100 & 450 & + & 0.335 \\
\hline 15 & 351 & 35.0 & $100 / 80$ & 18 & 3010 & II & 1000 & 1000 & & 0.334 \\
\hline
\end{tabular}

\section{Discussion}

High reliability of the created model was confirmed by the fact that as many as nine serious traffic accidents took place at the TOP-15 RLCs (Table 4) in 2012, which amounted to $60 \%(9 / 15=0.60)$. It should be noted that two accidents occurred after the development of the risk management model for the RLC at the Radviliškis station, which was ranked the most hazardous RLC (Table 4 , No 272 in the catalogue). In these accidents, one person was killed (in 2013) and one injured (in 2015). At the Lentvaris RLC (Table 4, catalogue No 111), which was ranked second according to its risk level, one person was fatally wounded in 2014 .

At the RLC of the Külupenai-Kretinga stretch (Table 4, catalogue No 348), which was ranked 13th, one person was also fatally wounded in 2012 .

When four traffic accidents, which took place in 2012-2014 and the first half of 2015 at the TOP-15 RLCs, were taken into account, the validity of the RLC safety risk model increased to $86 \%(13 / 15=0.86)$.

The developed model is flexible and can be easily adjusted. In the case of the increased safety of RLCs, the catalogue of their main data can be corrected and the ranks - recalculated. The considered model is universal and can be used for determining the safety risk to the infrastructures of other railway systems' elements (e.g. station tracking, railway yards, tunnels, viaducts, etc.) and for taking the required measures to prevent traffic accidents. This model can also be used for state monitoring of railway safety, which is performed in Lithuania by the Lithuanian State Railway Inspectorate (LSRI). Based on the above-described risk assessment model, LSRI in- spectors/decision-makers can draw up strategic and operational schedules for the inspection of infrastructure elements and plans for taking the priority measures for the reduction of the hazardousness of the railway system's objects.

\section{Conclusions}

1. Based on the research methods, the Authors offered the model created for managing traffic safety risk of Lithuanian level crossings, which can also be applied to assessing and managing traffic safety risk of level crossings in other countries.

2. The research has shown that road traffic intensity is the factor (criterion) highly increasing the hazardousness of level crossings. Traffic intensity is closely associated with the level crossing category (Table 2).

3. The second most important criterion is the visibility (distance $[\mathrm{m}]$ ) of a level crossing from the train driver's cab in both directions. Therefore, increasing the visibility of the roadbed near level crossings, which is usually insufficient (below $1000 \mathrm{~m}$ ), is the priority task, requiring such measures as the removal of bushes and other tall plants, as well as levelling of natural barriers (hills, slopes, cliffs, etc.), equipping panoramic mirrors, installing and upgrading the systems, etc.

4. The suggested methods of ranking level crossings according to their risk level, which are based on the logistic regression method, can be effectively used for determining the risk level of other elements of the railway system's infrastructure, such as railway yards, platforms, railway stretches, track switches, sets of station switches, sidings, and tunnels. 


\section{Acknowledgments}

The present study is a part of the Lithuanian Economic Growth Programme research project NoVP2-3.1-IVK03-V-01-008 'Creation of rail transport risk management and supervision public electronic service'. State Railway Inspectorate of Republic of Lithuania (SRIRL) initiated the project aimed at increasing the efficiency of railway risk control and management in the railway system of a country. The financial support received from SRIRL is gratefully acknowledged.

\section{References}

Austin, C.; Boehm, M.; Tooze, S. A. 2002. Site-specific crosslinking reveals a differential direct interaction of class 1,2 , and 3 ADP-ribosylation factors with adaptor protein complexes 1 and 3, Biochemistry 41(14): 4669-4677. http://doi.org/10.1021/bi016064j

Bonvicini, S.; Leonelli, P.; Spadoni, G. 1998. Risk analysis of hazardous materials transportation: evaluating uncertainty by means of fuzzy logic, Journal of Hazardous Materials 62(1): 59-74. http://doi.org/10.1016/S0304-3894(98)00158-7

Bureika, G.; Bekintis, G.; Liudvinavičius, L.; Vaičiūnas, G. 2013. Applying analytic hierarchy process to assess traffic safety risk of railway infrastructure, Eksploatacja i niezawodność Maintenance and Reliability 15(4): 376-383.

Cacciabue, P. C. 2005. Human error risk management methodology for safety audit of a large railway organisation, Applied Ergonomics 36(6): 709-718.

http://doi.org/10.1016/j.apergo.2005.04.005

Chang, H.-L.; Ju, L.-S. 2008. Effect of consecutive driving on accident risk: a comparison between passenger and freight train driving, Accident Analysis \& Prevention 40(6): 18441849. http://doi.org/10.1016/j.aap.2008.07.009

Davey, J.; Wallace, A.; Stenson, N.; Freeman, J. 2008. The experiences and perceptions of heavy vehicle drivers and train drivers of dangers at railway level crossings, Accident Analysis \& Prevention 40(3): 1217-1222.

http://doi.org/10.1016/j.aap.2008.01.005

De Giorgio, F.; Polacco, M.; Pascali, V. L.; Oliva, A. 2006. Death due to railway-related suicidal decapitation, Medicine, Science and the Law 46(4): 347-348.

http://doi.org/10.1258/rsmmsl.46.4.347

El Koursi, E.; M.; Mitra, S.; Bearfield, G. 2007. Harmonising safety management systems in European railway sector, Safety Science Monitor 11(2): 1-14.

Evans, A. W. 2003. Estimating transport fatality risk from past accident data, Accident Analysis \& Prevention 35(4): 459472. http://doi.org/10.1016/S0001-4575(02)00024-6

Famoye, F.; Wulu, J. T.; Singh, K. P. 2004. On the generalized Poisson regression model with an application to accident data, Journal of Data Science 2: 287-295.

Forsberg, R.; Björnstig, U. 2011. One hundred years of railway disasters and recent trends, Prehospital and Disaster Medicine 26(5): 367-373.

http://doi.org/10.1017/S1049023X1100639X

Hu, S.-R.; Li, C.-S.; Lee, C.-K. 2010. Investigation of key factors for accident severity at railroad grade crossings by using a logit model, Safety Science 48(2): 186-194. http://doi.org/10.1016/j.ssci.2009.07.010

Ishak, S. Z.; Yue, W. L.; Somenahalli, S. 2010. Level crossing modelling using petri nets approach and П-Tool, Asian Transport Studies 1(2): 107-121.
Lerner, N. D.; Llaneras, R. E.; McGee, H. W.; Stephens, D. E. 2002. Traffic Control Devices for Passive Railroad-Highway Grade Crossings. National Cooperative Highway Research Program (NCHRP) Report 470. Transportation Research Board Washington, DC, US.

Liu, R.; Huang, Z; Hao, W. 2011. Potential issues and challenges in implementing the railroad safety improvement act of 2008 based on a national survey, Journal of Transportation Safety \& Security 3(4): 252-271. http://doi.org/10.1080/19439962.2011.607937

Lobb, B. 2006. Trespassing on the tracks: a review of railway pedestrian safety research, Journal of Safety Research 37(4): 359-365. http://doi.org/10.1016/j.jsr.2006.04.005

Miranda-Moreno, L.; Fu, L.; Saccomanno, F.; Labbe, A. 2005. Alternative risk models for ranking locations for safety improvement, Transportation Research Record: Journal of the Transportation Research Board 1908: 1-8. http://doi.org/10.3141/1908-01

Mok, S. C.; Savage, I. 2005. Why has safety improved at railhighway grade crossings?, Risk Analysis 25(4): 867-881. http://doi.org/10.1111/j.1539-6924.2005.00642.x

Oh, J.; Washington, S. P.; Nam, D. 2006. Accident prediction model for railway-highway interfaces, Accident Analysis \& Prevention 38(2): 346-356. http://doi.org/10.1016/j.aap.2005.10.004

Podofillini, L.; Zio, E.; Vatn, J. 2006. Risk-informed optimisation of railway tracks inspection and maintenance procedures, Reliability Engineering \& System Safety 91(1): 20-35. http://doi.org/10.1016/j.ress.2004.11.009

Saccomanno, F.; Fu, L.; Miranda-Moreno, L. 2004. Risk-based model for identifying highway-rail grade crossing blackspots, Transportation Research Record: Journal of the Transportation Research Board 1862: 127-135.

http://doi.org/10.3141/1862-15

Tey, L.-S.; Ferreira, L.; Wallace, A. 2011. Measuring driver responses at railway level crossings, Accident Analysis \& Prevention 43(6): 2134-2141.

http://doi.org/10.1016/j.aap.2011.06.003

Tu, J.; Cheng, R.; Tao, Q. 2015. Maintenance strategy decision for avionics system based on cognitive uncertainty information processing, Eksploatacja i niezawodność - Maintenance and Reliability 17(1): 156-163.

Wullems, C. 2011. Towards the adoption of low-cost rail level crossing warning devices in regional areas of Australia: a review of current technologies and reliability issues, Safety Science 49(8-9): 1059-1073.

http://doi.org/10.1016/j.ssci.2011.04.006

Yan, X.; Richards, S.; Su, X. 2010. Using hierarchical tree-based regression model to predict train-vehicle crashes at passive highway-rail grade crossings, Accident Analysis \& Prevention 42(1): 64-74. http://doi.org/10.1016/j.aap.2009.07.003

Ye, X.; Pendyala, R. M.; Shankar, V.; Konduri, K. C. 2013. A simultaneous equations model of crash frequency by severity level for freeway sections, Accident Analysis \& Prevention 57: 140-149. http://doi.org/10.1016/j.aap.2013.03.025

Ye, X.; Pendyala, R. M.; Washington, S. P.; Konduri, K.; Oh, J. 2009. A simultaneous equations model of crash frequency by collision type for rural intersections, Safety Science 47(3): 443-452. http://doi.org/10.1016/j.ssci.2008.06.007 